\title{
MANAGEMENT OF THE ANTICOAGULATED PATIENT FOR OPHTHALMIC SURGERY
}

\author{
P. McCORMACK, P. R. SIMCOCK and A. B. TULLO \\ Manchester
}

\begin{abstract}
SUMMARY
The outcome of 50 surgical procedures in 41 patients who were anticoagulated at the time of surgery were reviewed to determine whether anticoagulation was associated with an increase in ophthalmic morbidity. Twenty-seven patients were receiving warfarin and 14 patients nicoumalone. The International Normalised Ratio (INR) was determined immediately prior to surgery and ranged from 1.1 to 4.9. Thirty-nine operations were performed under local anaesthetic and 11 under general anaesthetic. Thirty-three patients had extracapsular cataract extractions with posterior chamber lens implantation. No major haemorrhagic complications were associated with the local anaesthetic or the surgical procedure. Patients on anticoagulation therapy are at risk of life-threatening complications if their anticoagulation is stopped or reduced. This study demonstrates that most ophthalmic surgical procedures can be safely performed whilst the patient is therapeutically anticoagulated.
\end{abstract}

Many patients undergoing ophthalmic surgery are on long-term oral anticoagulation. There are no clear guidelines in the literature regarding the management of the anticoagulated patient undergoing ophthalmic surgery. These patients are often elderly and at risk of life-threatening thromboembolic complications if their anticoagulation is discontinued. ${ }^{1,2}$ Ophthalmic surgical procedures (with the exception of major lid and orbital surgery) are usually associated with minimal blood loss. This study investigated patients who remained anticoagulated during surgery to determine whether this was associated with an increase in haemorrhagic ophthalmic morbidity.

\section{PATIENTS AND METHODS}

All patients taking oral anticoagulants who were admitted to the Manchester Royal Eye Hospital for surgery between September 1991 and September 1992 were prospectively evaluated. Detailed information about each patient was

From: Royal Eye Hospital, Manchester, UK.

Correspondence to: P. McCormack, FRCS, FRCOphth, Princess Alexandra Hospital, Royal Air Force Wroughton, Swindon, Wiltshire SN4 0QJ, UK. recorded, including age, sex, reason for anticoagulation, anticoagulant dosage, type of anaesthesia, operation performed and any complications of the procedure. The International Normalised Ratio (INR) was obtained on the day prior to surgery.

\section{RESULTS}

Forty-one patients undergoing 50 surgical procedures who were anticoagulated at the time of surgery were included in the study. Twenty-seven patients were taking warfarin and 14 patients nicoumalone. The reasons for anticoagulation are shown in Table I. Eleven patients had their oral anticoagulation stopped 1-5 days prior to surgery but remained anticoagulated as measured by the INR on the day before surgery. Fig. 1 shows the INR of the patients immediately prior to surgery.

Twenty-two operations were performed using retrobulbar anaesthesia, 16 using peribulbar anaesthesia and 1 patient undergoing vitreoretinal surgery had a combination of an initial peribulbar injection followed by direct intraconal 'top-up' infiltration with a curved lacrimal cannula. Eleven operations were performed with general anaestheisa. Table II shows the type of surgery performed. Those patients undergoing cataract surgery had extra-

Table I. Reasons for anticoagulation

\begin{tabular}{lc}
\hline Medical condition & No. of patients \\
\hline Atrial fibrillation & 14 \\
Heart valve pathology & 11 \\
Deep vein thrombosis/pulmonary embolism & 8 \\
Other & 8 \\
\hline
\end{tabular}

Table II. Type of surgery performed

\begin{tabular}{lc}
\hline Type of surgery & No. of operations \\
\hline Extracapsular cataract extraction with posterior & \\
chamber intraocular lens & 33 \\
Vitreoretinal surgery & 8 \\
Trabeculectomy & 5 \\
Everting lid sutures & 2 \\
Secondary anterior chamber intraocular lens implant & 1 \\
Trans-septal orbital biopsy & 1 \\
\hline
\end{tabular}




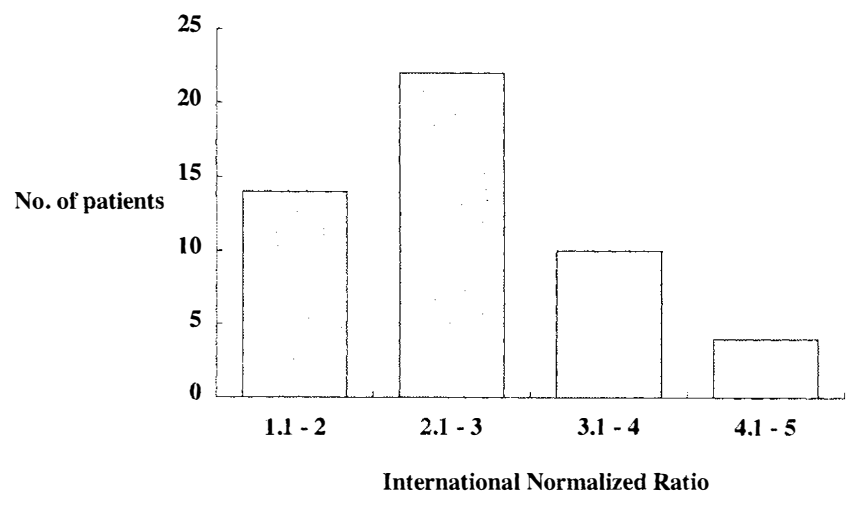

Fig. 1. Degree of anticoagulation of patients prior to surgery.

capsular extractions with a posteriorly placed corneal section that just incised the limbal vascular arcades.

No patient had significant haemorrhagic complications. One patient had brisk bleeding from a cataract section but no post-operative hyphaema was noted. Three patients had small hyphaemas following glaucoma filtration surgery. There were no complications from the administration of local anaesthesia.

\section{DISCUSSION}

Several previous studies have questioned the need for stopping oral anticoagulation prior to ocular surgery. ${ }^{3-6}$ Stone et al. ${ }^{1}$ sent a questionnaire to 200 members of the American Intraocular Lens Implant Society, looking at attitudes to the use of anticoagulation and aspirin over the peri-operative period for cataract surgery. They found that 105 surgeons routinely discontinued anticoagulation 3-5 days before surgery. Only 10 surgeons continued with anticoagulation. No complications of surgery were reported by those surgeons who continued anticoagulation. Two deaths and 7 non-fatal thromboembolic epi- sodes were reported from those surgeons who withheld anticoagulation.

Our results show that the ophthalmic surgical procedures in this study can be safely performed whilst the patient is therapeutically anticoagulated, thereby maintaining adequate prophylaxis against thromboembolic disease.

Patients having complex lid, lacrimal and orbital surgery were excluded from this study. We would recommend changing to intravenous heparin therapy to facilitate more accurate control of anticoagulation during surgery in these cases. ${ }^{6}$ This requires close consultation with the haematologist and physician concerned with the patient's care, in order to maintain a minimum safe degree of anticoagulation for the shortest possible time during the surgery.

Key words: Anticoagulants, Cataract extraction, Eye haemorrhage, Warfarin.

\section{REFERENCES}

1. Stone LS, Kline OR Jr, Sklar C. Intraocular lenses and anticoagulation and antiplatelet therapy. Am Intra-ocular Implant Soc J 1985;II:165-8.

2. Moll AC, Van Rij G, Van Der Loos TLJM. Anticoagulant therapy and cataract surgery. Doc Ophthalmol 1989;72: 367-73.

3. Gainey S, Robertson D, Fay W, Ilstrup D. Ocular surgery on patients receiving long term warfarin therapy. Am J Ophthalmol 1989;108:142-6.

4. Hall DL, Steen WH, Drummond JW, Byrd WA. Anticoagulants and cataract surgery. Ophthalmic Surg 1988;19:221-2.

5. McMahan L. Anticoagulants and cataract surgery. J Cataract Refract Sug 1988;14:569-70.

6. Cruckshank MK, Levine MN, Hirsh J, Roberts R, Siguenza M. A standard heparin nomogram for the management of heparin therapy. Arch Intern Med 1991;151:333-7. 